\title{
Managing carbon footprint for a sustainable supply chain: a systematic literature review
}

Managing carbon footprint

Piya Ghosh Department of Industrial and Management Engineering, IIT Kanpur, Kanpur, India Ajay Jha

Department of Transportation Management, University of Petroleum and Energy Studies, Dehradun, India, and RRK Sharma Department of Industrial and Management Engineering, IIT Kanpur, Kanpur, India

\begin{abstract}
Purpose - The carbon emissions due to industrial production and market consumption activities are the major contributors to global warming. With the signing of UN Paris Accord 2016 on climate change, the world's major countries are devising measures to combat climate change and attain a sustainable, low-carbon future. Globalization demands companies not only to adopt greener manufacturing practices internally for reduced carbon footprint (CFP) but beyond its boundaries (i.e. its supply chain). This study aims to discuss the relationship between CFP and sustainable supply chain, as evident in the current literature and industry practices. It provides a total comprehension of past, present and future headings in the CFP area and its contribution to a sustainable supply chain.

Design/methodology/approach - A systematic literature review and analysis have been undertaken in supply chain sustainability and CFP. A bibliometric approach is adopted for this investigation, and one of the biggest computerized databases, "Scopus," has been picked. In total, 37 articles have been zeroed in after a careful and watchful screening of firmly related topics.

Findings - Most researchers gave predominance to environmental impact among the three pillars of sustainability (economy, society and the environment) for a sustainable supply chain environment. Only a few researchers were motivated to cover social development and social responsibility aspects. This review highlights how managing a CFP is one of the significant attributes of sustainable development. Existing literature in the field of CFP and sustainability have been written on actual industry cases. Food, electricity and energy are some significant industries where supply chain sustainability successfully reduces carbon emission.

Originality/value - The theory-building strategy with recommendations on the conceptualization of a sustainable supply chain is limited in the literature. This study gives broad ideas on how organizations modified and redeveloped different tools and technologies to make their supply chain more sustainable. The strategic role of different carbon policies, environmental rules and regulations in the domain of CFP is also recognized in this work. This study highlights the biases of most of the researches toward applications than policy interventions. This study discusses the theoretical perspective about how CFP affects supply chain management and helps organizations and researchers develop a new set of approaches in handling CFP and other sustainability aspects.
\end{abstract}

Keywords Carbon footprint, Sustainability, Sustainable supply chain, Global supply chain

Paper type Research paper

(C) Piya Ghosh, Ajay Jha and RRK Sharma. Published in Modern Supply Chain Research and Applications. Published by Emerald Publishing Limited. This article is published under the Creative Commons Attribution (CCBY 4.0) license. Anyone may reproduce, distribute, translate and create derivative works of this article (for both commercial and non-commercial purposes), subject to full attribution to the original publication and authors. The full terms of this license may be seen at http://creativecommons. org/licences/by/4.0/legalcode

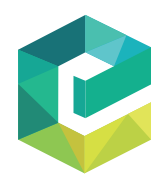


MSCRA

2,3

124

\section{Introduction}

In the 21st century, "sustainability" is one of the essential terms for all kinds of the organizations because of its essential role in the profitable growth of the companies as well as the preservation of social and environmental value (Corbett and Klassen, 2006; Kolk and Pinkse, 2008). Among the three pillars of sustainability, the concern for environmental degradation is predominately influencing the practices of global industries and governmental policies. The movement initially took off in the late 1990s, when increased awareness and consciousness about the "carbon footprint" (CFP) and global warming are witnessed. The Kyoto Protocol (United Nations, 1997) asked to reduce greenhouse gases in the atmosphere, and approximately 150 countries ratified to adopt this protocol in their industrial policy. Further, an assessment report by the Intergovernmental Panel on Climate Change (IPCC, 2007) established that greenhouse gases severely affect our environment. Various regulatory and transaction measures like Emission Trading System, Carbon cap and trade and Carbon tax were devised by different countries in their sustainability policies (Gonzalez et al., 2009).

Organizations are progressively thoughtful and responsive to the carbon emission in today's world, which relates to their organizational operations (Colette and Venkat, 2009; Stock et al., 2010). In the Carbon Disclosure Project (2011) annual report, companies like WalMart, Pepsi, Coca-Cola, Volkswagen and Ericsson promised to set up "carbon target." Companies started using eco-friendly machines, less polluting vehicles and greener operational processes to reduce their CFP. In this scenario, the customers played a significant role when they increased their socially/environmentally conscious consumption practices. With increased concern about global warming, environmental safety and societal impact among consumers, organizations adopt sustainable strategies (Gold et al., 2010). Researchers found that adopting sustainable strategies reduces the greenhouse effects and carbon emissions in the environment (Gandhi et al., 2015; Luthra et al., 2014). Much research has addressed sustainable supply chain management issues like green purchasing, reverse logistics and green manufacturing (Bai and Sarkis, 2010; Eltayeb et al., 2011). In a few decades, lots of research on supply chain management's CFP proves the growing importance of environmental costs in the supply chain strategy.

This study dwells on the literature review in sustainable operations and tries to establish the importance of the CFP in sustainable supply chain management. It answers how organizations develop sustainable supply chains to reduce the CFP. In sections 2 and 3, we discuss the concepts of the sustainable supply chain and CFP. That is followed by the research methodology and the details of related literature. The findings and conclusions of this review are provided in the last section and future research ideas.

\section{Sustainable supply chain management}

Supply chain management is about managing a network of links where goods or services get delivered to the customer best. In a sustainability context, it gives organizations the capacity to accumulate information about how well every part of the supply chain exhibits social and environmental duty. The Report of the World Commission on Environment and Development: Our Common Future gave the universally accepted definition for sustainable development (Brundtland et al., 1987). The "triple bottom-line" approach was proposed (Elkington, 1994) that considered besides the profit and loss, maintaining social and environmental values. The main aim of a supply chain is economic growth, which means improving the profit and reducing the loss (Goetschalcks and Fleischmann, 2008; Nagurney, 2010a, 2010b), but the triple bottom-line approach calls for a balance of three objectives. In a sustainability context, the literature on supply chain management imparts a more significant role to government and society's pressures in industries' drive toward sustainable supply chain practices. 
In the literature, different researchers define sustainable supply chain management in their ways. We can say that a supply chain can efficiently deliver any kind of socially valuable goods or services without harming the environment as a sustainable supply chain. Though there are tradeoffs between efficiency and sustainability goals, a sustainable supply chain can create long-term profit. If we go through some significant definitions for a sustainable supply chain (Table 1), we can see that it mainly focuses on three integrated terms: economic performance, environmental care and social responsibility. The triple bottom-line approach in brief is:

\section{(1) Economic performance}

It indicates the organizational/player's profits, which involves the money flow over the supply chain. The firms are participating in the supply chain to make a profit and grow.

(2) Environmental care

It is mainly concerned with environmental safety and preservation. An organization should focus on preventing pollution, avoiding excessive use of natural resources, biodegradable products and reuse.

\section{(3) Social responsibility}

It refers to the social dimension. Organizations need to focus on a safe working environment. They should avoid child laborers or forced laborers. Of course, they have to make positive contributions to society.

Researchers discovered that there are six ways to make supply chain management more sustainable. Those are (1) an organization needs to identify the critical areas of its old supply

\begin{tabular}{|c|c|c|c|}
\hline Author & Year & Definition & \\
\hline Shrivastava & 1995 & $\begin{array}{l}\text { Decrease of dangers happening in the long haul in a flexible chain related to asset } \\
\text { use, vitality usage and related costs, item structure, contamination and waste } \\
\text { administration }\end{array}$ & \\
\hline Beamon & 1999 & $\begin{array}{l}\text { An extended supply chain aims to minimize the environmental impacts of a product } \\
\text { throughout its entire life cycle; such as green design, resource-saving, harmful } \\
\text { material reduction and product recycling }\end{array}$ & \\
\hline $\begin{array}{l}\text { Jørgensen and } \\
\text { Knudsen }\end{array}$ & 2006 & $\begin{array}{l}\text { How companies manage their social responsibilities across dislocated production } \\
\text { processes spanning organizational and geographical boundaries }\end{array}$ & \\
\hline Font et al. & 2008 & $\begin{array}{l}\text { Adding sustainability to the existing supply chain the executive's forms, to think } \\
\text { about natural, social and monetary effects of business exercises }\end{array}$ & \\
\hline Haake and Seuring & 2009 & $\begin{array}{l}\text { The arrangement of the supply chain the executives approaches held, activities } \\
\text { taken and connections framed in light of concerns identified with the typical habitat } \\
\text { and social issues about the structure, procurement, creation, circulation, use, reuse } \\
\text { and removal of the association's merchandise and ventures }\end{array}$ & \\
\hline $\begin{array}{l}\text { Wittstruck and } \\
\text { Teuteberg }\end{array}$ & 2012 & $\begin{array}{l}\text { An extension of the traditional concept of supply chain management by adding } \\
\text { environmental and social/ethical aspects }\end{array}$ & \\
\hline Diabat et al. & 2014 & $\begin{array}{l}\text { Analysis of enablers for implementation of sustainable supply chain management- } \\
\text { a textile case }\end{array}$ & \\
\hline Panigrahi et al. & 2019 & $\begin{array}{l}\text { All the partners in the supply chain must cooperate to accomplish sustainability } \\
\text { objectives. Associations will stay hesitant to focus on sustainability norms until } \\
\text { specific laws have not been authorized }\end{array}$ & \\
\hline Koberg and Longoni & 2019 & $\begin{array}{l}\text { By and large, designs described by a more prominent association between the } \\
\text { central firm and multi-level providers, oversaw legitimately or through outsiders, } \\
\text { are expanding patterns proposed serving supportability advancement better }\end{array}$ & Table 1. \\
\hline Cole and Aitken & 2020 & $\begin{array}{l}\text { In a reasonable, flexible chain, the executives, purchasers may utilize middle people } \\
\text { to connect trades with providers when information on appropriate manageability } \\
\text { rehearses is frail and needing assistance }\end{array}$ & $\begin{array}{l}\text { SSCM definitions in the } \\
\text { literature (source: } \\
\text { Panigrahi et al., 2019) }\end{array}$ \\
\hline
\end{tabular}

Managing carbon footprint 
MSCRA

2,3

126

chain where it can implement different operational processes to minimize environmental impact; (2) organizations need to set up some tools to track the progress of the new measurement requirements and find out the weaknesses; (3) organizations should decide some goals for them, as per the government regulation and capability of the research team; (4) try to collaborate with different sustainable links, namely, suppliers for raw materials, logistics; (5) try to maintain a transparent supply chain; and (6) organizations can buy offsets for their CFP and can contribute to different social engagement. The literature on the sustainable supply chain discusses product design, operational changes over the supply chain, more sustainable raw materials, reverse logistics. Raw material selection or purchasing is one of the significant parts of any kind of supply chain. Environmental purchasing or green purchasing can reduce the environment's risk and make the supply chain more sustainable (Zsidisin and Siferd, 2001). Michelsen et al. (2006) studied a furniture supply chain to explore how eco-efficiency can be included with the traditional supply chain. They compared the environmental value of the sustainable supply chain with the traditional one. Adopting sustainable supply chain practices is on the rise in the 21st century. A study confirms that nearly $75 \%$ of the big international companies have adopted sustainable supply chains instead of their traditional ones (Hubbard, 2009).

Research in the measurement of CFP in supply chain processes is also given due weightage. Sundarkani et al. (2010) used Lagrangian and the Eulerian transport method to measure the supply chain's CFP. Researchers suggested that $\mathrm{CO}_{2}$ emission from different stages of the supply chain creates a substantial environmental impact. Caniato et al. (2012) have studied the supply chains of five different fashion organizations and three factors that could help build environmental sustainability. Based on the triple bottom-line approach, Govindan et al. (2013) measured a supplier selection's sustainability performance using a fuzzy multi-criteria approach. Using fuzzy analytic hierarchy process (AHP), a sustainable supply chain evaluation model was implemented in the publishing industry by Shaverdi et al. (2013). A sustainable manufacturing model focusing on leather industries was produced (Dwivedi et al., 2019). Shardeo et al. (2020) suggested an information and decision synergy model for sustainable freight transportation. Further, critical success factors for blockchain adoption in sustainable freight transportation was suggested (Shardeo et al., 2020).

\section{Carbon footprint}

Today's world is more concerned about "carbon footprint." The amount of $\mathrm{CO}_{2}$ and other greenhouse gases emitted to the environment due to direct or indirect human activity is called the CFP. It is one of the primary reasons for global warming and the exhaustion of natural resources. If we discuss greenhouse gas emissions in an organization, we must say that three different emissions are noticed. These are:

\section{(1) Direct emission}

It indicates the number of greenhouse gases emitted directly to the environment because of different organizational functions, such as producing energy and measuring the amount of carbon dioxide produced or emitted in the atmosphere. In fertilizer usage, nitrous oxide $\left(\mathrm{N}_{2} \mathrm{O}\right)$ emitted to the environment contributes to an environmental hazard. All these emissions can be controlled by adopting environment-friendly processes.

(2) Indirect emission

This type of emissions is not directly under our control. The goods or services that an organization is using or manufacturing that indirectly help $\mathrm{CO}_{2}$ emissions. The firm transports its goods or services from one place to another; the amount of $\mathrm{CO}_{2}$ emitted from transportation mode can be considered indirect transmission. 


\section{(3) Emission because of electricity}

Every firm uses electricity, and they have to buy that from different other organizations. There are different electricity sources present, but in the world, significant sources are coal, natural gas, nuclear energy. So, the firm has no direct control, but somehow they are also responsible for this emission.

Nowadays, organizations want to calculate their CFP because they want to maintain and reduce their CFP. It can be the initial step for any firm to maintain carbon emissions and create an efficient environmental management system. In the past ten years, different organizations have adopted many operational and strategic changes to reduce their CFP. Researchers discussed and proposed several solutions for different carbon issues over supply chain management. One such strategy is the "carbon trading system" by which an organization can reduce its CFP obligations. Under carbon cap situations, carbon price is considered with a traditional economic order quantity (EOQ) model. Then, firms can determine their optimal ordering amount, which can help manage the CFPs in their inventory management (Hua et al., 2011). A mixed-integer linear program (MILP) to handle emission trading is proposed by Chaabane et al. (2012). The model describes effective carbon management strategies to achieve a sustainable supply chain. An organization can reduce its $\mathrm{CO}_{2}$ emission by changing or modifying their operational decisions. Benjaafar et al. (2012) considered different carbon emission constraints in a single-item incapacitated lot-sizing problem. The constraints focused on the limitation of carbon emission for each unit product shipment and mode of shipments. This paper mentions four new emission constraints (periodic, cumulative, global and rolling carbon emission). Models with periodic carbon emission constraints can be solved in polynomial time, and for that, a dynamic had to be developed (Absi et al., 2013). The traditional EOQ model considers environment policies, total carbon emissions, price and dependent environmental demands. It provides solutions in different situations to increase the organization's profit and reduce carbon emission (Hovelaque and Bironneau, 2015). The carbon cap and trade mechanism can be remanufactured in ordinary and green markets (Chai et al., 2018). Identification of key performance indicators and issues for implementation of circular economy in an informationfacilitated product recovery system was suggested (Dwivedi and Madaan, 2020; Dwivedi et al., 2020).

\section{Review procedure}

A literature review is a significant part of any research or project and should be done correctly. Over time, researchers described the proper procedures for systematic literature review and discussed the research methodology (Tranfield et al., 2003; Dubey et al., 2017; Gupta et al., 2020).

\subsection{Searching the literature}

This literature search objective was to find the existing literature in the sustainable supply chain area, affected explicitly by CFP. There are different digital databases like Scopus, IEEE Xplore, EBSCO. However, we chose Scopus for our literature review. Scopus is one of the largest and most commonly used digital databases for any academic journals, proceedings and book chapters. It also provides opportunities to search for documents from more than 25 different subject areas like engineering, management, physics, medicine, arts and humanities.

In our study, we considered two keywords - "carbon footprint" and "sustainable supply chain." The documents related to these two terms were searched using "OR" and "AND" operators. These two operators work similarly as Boolean operators. Table 2 provides the syntax for a systematic literature search. This search was done on April 12, 2020.

Managing carbon footprint 
MSCRA 2,3

128

Researchers prefer to publish their papers in journals compared to conferences. That was the reason we limited our search to only articles in reputed journals. The selected articles after the search process were taken as an authentic impression of the information. The search results can be verified by simply copying and pasting the search syntax to www.scopus.com. The different stages of the literature screening process are described in Figure 1. Initially, the search was done on the keyword "Carbon Footprint" or "carbon footprint." The search returns 15,976 documents.

\begin{tabular}{ll}
\hline Data source & Search syntax \\
\hline Search performed on April 12, 2020, & ((TITLE-ABS-KEY(“Carbon Footprint”) OR TITLE-ABS- \\
at: www.scopus.com & KEY(“carbon footprint”))) AND ((TITLE-ABS-KEY(“sustainable \\
& supply chain”) OR TITLE-ABS-KEY(“supply chain sustainability”)) \\
& AND (LIMIT-TO (DOCTYPE,"ar”) OR LIMIT-TO (DOCTYPE,"re”)) \\
& AND (LIMIT-TO (LANGUAGE,“English”)) AND (LIMIT-TO \\
& (SRCTYPE,“j”))
\end{tabular}

Table 2.

Table for search syntax

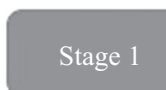

Stage 2

Stage 3

Stage 4

Stage 5

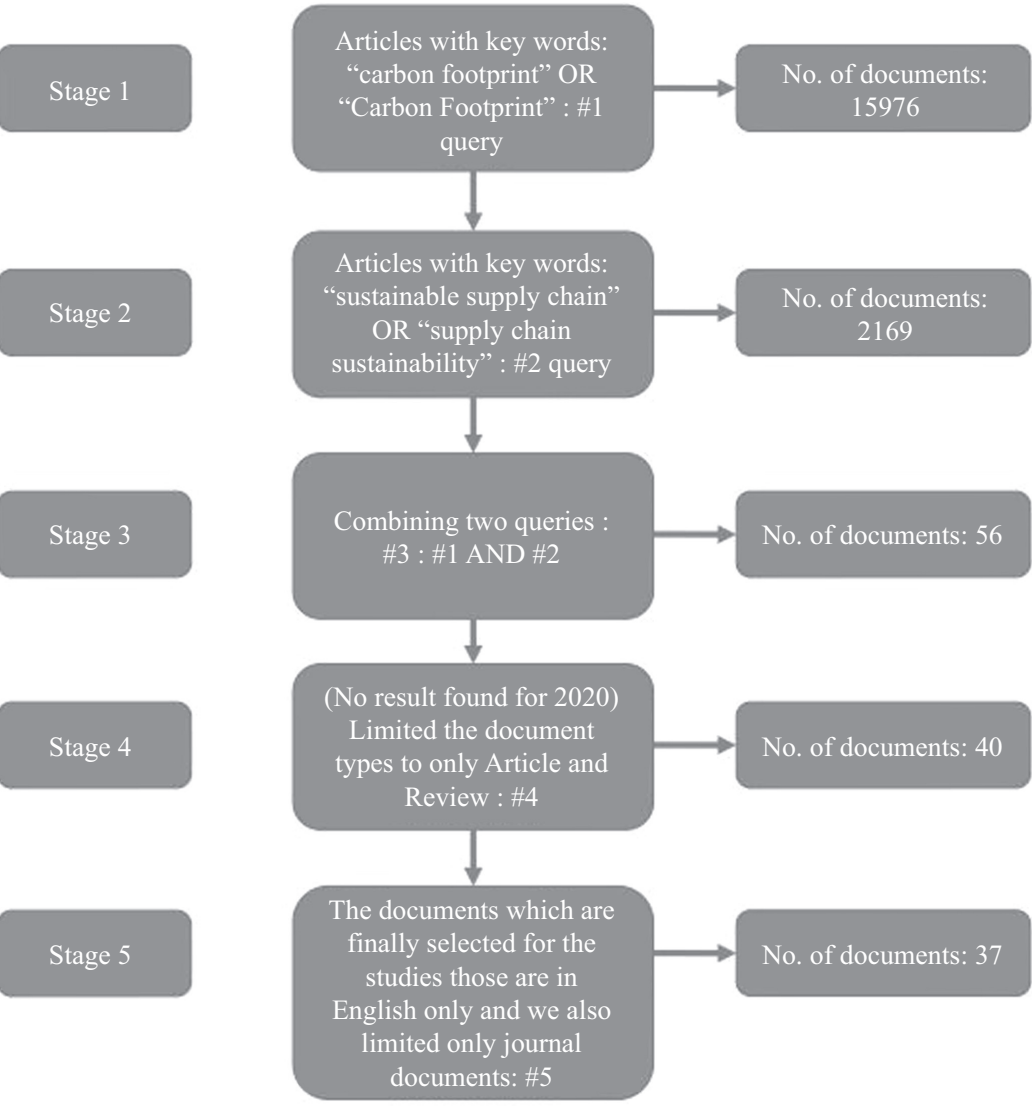

Figure 1.

The stepwise search process for data collection 
In the next step, we did a separate search for the keyword "sustainable supply chain" or "supply chain sustainability." The result was 2,169 documents. Further, we combined the first two searches using the "AND" operator. It returned only 56 documents. We have not found any documents that were published in 2020. It returned only 40 documents. Finally, we choose only 37 documents that are in the English language. These 37 documents are the final documents for our literature review. These documents were published in different reputed journals. Table 3 shows that the Journal of Cleaner Production, Sustainability Switzerland, International Journal of Production Economics are major journals for publication.

\subsection{Classifying selected literature}

We chose the most relevant 37 documents for review. Figure 2 shows the different academic fields in which this type of research has been undertaken. The maximum research work is observed in the domains of environmental science and engineering.

Figure 3 gives the yearwise frequency of research papers published in the CFP and sustainability domain. It indicates that after 2017, the number of research publications in this area gained importance among the researchers.

Figure 4 gives the idea about countries publishing more numbers of papers in this field.

We were able to conclude that the maximum number of papers were published in the USA. Countries like China, the UK are also adopting sustainable supply chains because of the CFP.

\section{Discussion of selected literature}

The resulting 37 articles helped us to identify CFP linkages with a sustainable supply chain. We summarize the findings of these research papers as follows. Most articles can be classified into two categories: researchers done the case studies over a particular type of industry, and

Name of the journal No. of documents published

Journal of Cleaner Production Sustainability Switzerland International Journal of Production Economics

Resources Conservation and Recycling Applied Energy

Business Strategy and the Environment

Journal of Environmental Management

Applied Sciences Switzerland

Computers and Industrial Engineering

Computers and Operations Research

Environmental Research Letters

European Journal of Operational Research

IFAC Papers Online

International Journal of Environmental Research and Public Health

International Journal of Life Cycle Assessment

International Journal of Production Research

Journal of Industrial Engineering and Management

Journal of Manufacturing Technology Management

Journal of Remanufacturing

Journal of Transport Geography

Mathematical Problems in Engineering

Nature

Opsearch

Production Planning and Control
Managing carbon footprint
Table 3.

Articles published in different journals 
MSCRA

2,3

\section{0}

Figure 2.

Range of journal papers based on their research area

Figure 3.

Number of documents published per year

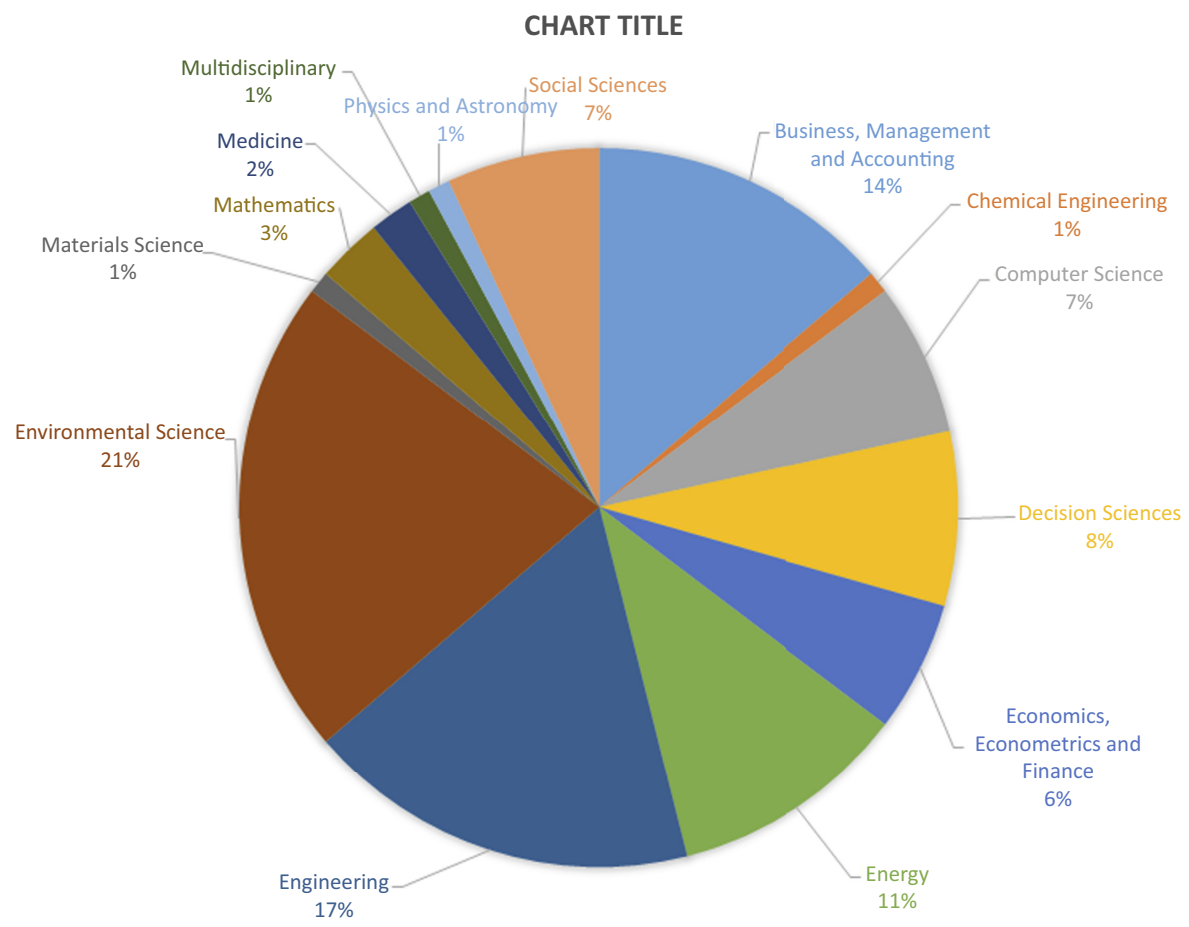

No of documents Vs Year

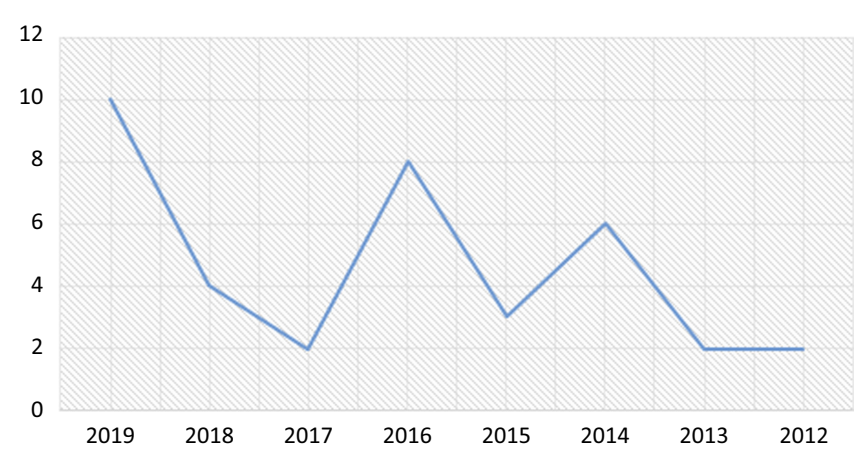

second, where researchers came up with new operational strategies or models for a particular industry type. In both of the cases, they focused on three major industries.

\subsection{Industry classification}

5.1.1 Food industries. The sustainable food supply network is the future goal for many governments, organizations and researchers. Many studies had been done that show that the food supply chain network emitted a tremendous amount of greenhouse gases in the environment. Food manufacturing is one of the essential parts of the US economy, but 


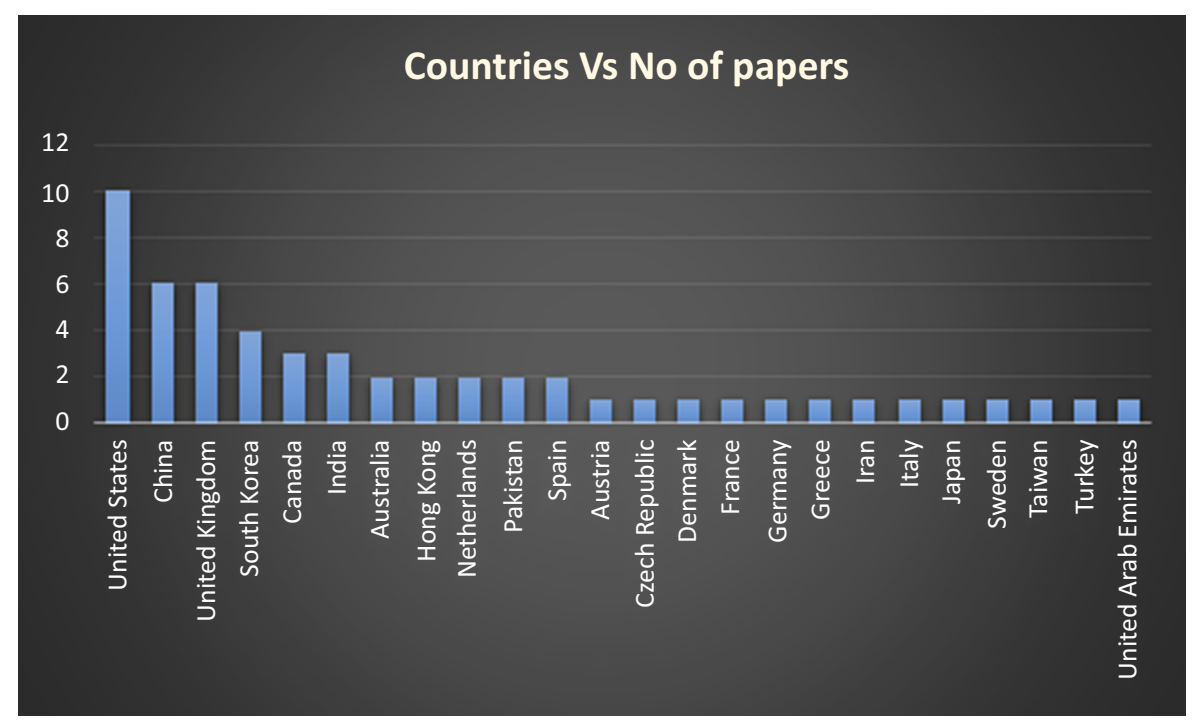

Managing carbon footprint

131

Figure 4. Countries of published papers

researchers found that most food manufacturers could not develop sustainable supply chains. The researchers' findings helped the policymakers understand how they can develop a more sustainable supply chain for food industries (Egilmez et al., 2014). A multi-objective sustainable perishable food supply chain network model was proposed with two echelons' location routing problem. This model reduces the carbon cost over the supply chain. It was observed that hybrid methods returned better solutions in large or medium or small problems (Govindan et al., 2014). In the case of food product distributions, logistics is a significant part of the supply chain. A lot of CFP is generated in the processing, transportation and storage of food products. The optimum choice of a "logistic service provider" can reduce the supply chain network's CFP. Kellner and Johannes (2015) showed that reducing greenhouse gas emissions is possible by adequately allocating transport and storage, even without implementing new or advanced technologies. They proved by modifying its logistic network or shipment decisions, and a firm can successfully reduce its carbon emission. Traditionally, suppliers of UK supermarkets focus mainly on their profit. A study considered UK supermarket sectors and suggested motivating the suppliers' behavior to reduce the emission (Tidy et al., 2016). This report discussed the social responsibilities of suppliers and retailers over the supply chain network. Environmental awareness among the customers is challenging conventional agro-food logistics practices. People pay comparatively extra attention to the freshness of their daily food items.

The government is also concerned about food safety. Organizations are trying to redevelop or modify their supply chain network to maintain sustainability throughout the supply chain. A study proposed a two-stage hybrid multi-objective model for developing a more sustainable supply chain for agro-food industries (Allaoui et al., 2018). This model helped to take different managerial decisions that focused on a triple bottom-line approach. Jiang et al. (2019) discussed a Chinese beverage company's case study, where they suggested a mixed-integer programming model. They validated different operational decisions and strategies that can maintain different uncertainties over a sustainable supply chain. They showed that if a small amount of carbon trading price varies, it will significantly impact a sustainable supply chain. A study was conducted to measure spatial 
MSCRA

2,3

132

greenhouse gas emissions in three major corn production sites of the USA (Pelton, 2019). In corn farming, different nitrogen-based fertilizers were used over the farming field, causing $\mathrm{N}_{2} \mathrm{O}$ emissions. That study used a "streamlined line life cycle assessment" method and identified high-risk locations and the indicators that increase emissions. Their results could help policymakers and organizations take proper action and operational decisions to reduce their emissions.

5.1.2 Electrical or chemical industries. Researchers also studied the "energy-climatemanufacturing nexus" in achieving a sustainable supply chain. Kucukvar et al. (2016) studied and observed that electricity and water supply sectors had a maximum CFP in the environment. Their study focused on Turkish manufacturing industries where they collected different global and regional supply parameters to calculate energy and carbon emissions in the environment. The results showed that during 2009, Turkish manufacturing sectors consumed large amounts of energy compared to countries like China, the USA and others. They also showed that, for any industrial sector, maximum energy is used in the upstream supply chain or manufacturer's time. This study could help future policymakers to understand the role of different industrial sectors in global warming, and according to that, they can improvise their future policies. A similar study focused on the electrical and chemical industries of 33 countries to calculate the total direct and indirect emissions of different greenhouse gases (Acquaye et al., 2017). The study accumulated the information regarding greenhouse gas emissions $\left(\mathrm{CO}_{2}, \mathrm{SO}_{2}\right)$ and water usage by electrical and chemical industries. They also studied the impact of these on the global environment. Researchers used a multi-regional input-output model for 15 years of long time-series data over the global supply chain. The result showed information about the performance of these two major global industries. They also discussed different roles of supply chain indicators in controlling the sustainability and discussed the industries' viewpoints and strategies for maintaining a global sustainable supply chain. They suggested choosing the indicators appropriately as per the supply chain data, where they can monitor the performance over different periods (Acquaye et al., 2017).

5.1.3 Energy industries. Sustainable development demands different advanced technologies and tools that optimize energy consumption and resources. That is the reason researchers focused on developing energy-efficient technologies. Sarkar et al. (2018) developed a multi-objective sustainable supply chain model for automobile industries, with objectives of minimization of energy cost and other resources. They used a weighted goal programming approach to solve the model. Organizations now focus not only on their energy savings, but also using different renewable energies. Researchers invested their knowledge to study different sustainable energy sources. Ahmed and Sarkar (2019) proposed a multiobjective sustainable supply chain model that included the concept of carbon trading, decreasing the environmental loss, improving the social responsibilities and using renewable energies like biofuel. They considered fuzzy modeling for uncertain market demand and variable costs. Their goal was to develop a sustainable supply chain that limits the total carbon outflows and expands new jobs in sustainable energy sectors. Another group of researchers discussed the logistic problem associated with this renewable energy use (Sadeghi and Haapala, 2019). They proposed a mathematical model for biomass (bio-oil) supply chain and used genetic algorithms to solve it. The result gave the idea about the optimum number of trucks for delivery, warehouses for inventory and refiners.

\subsection{Supply chain and different decisions}

Researchers also focused on providing better operational strategies for making the existing supply chain more sustainable. To achieve a sustainable supply chain is challenging because of the market and environmental uncertainties. 
5.2.1 Operational decisions for sustainable supply chain. Researchers suggested different tools and techniques for measuring the exact amount of CFP for any organization to achieve sustainability. For example, if an organization uses a shared warehouse instead of a fully dedicated one, it can reduce operations costs. Mallidis et al. (2012) proposed a methodology for a South-Eastern European company. They observed that if environmental issues like minimization of $\mathrm{CO}_{2}$ emission were combined with existing supply chain objectives, it would not create a massive difference in supply chain cost. They also observed that if an organization shared some warehouse or transportation modes with others, they could reduce the average emission of $\mathrm{CO}_{2}$ from their supply chain. This was suggested for shared warehouses and logistics as a cost-effective and environment-friendly strategy.

Most of the organizations focused on direct carbon emissions, but indirect emission can also increase their CFP. Cordero (2013) prepared a literature review that examined how existing technologies and strategies could calculate the CFP over a supply chain. This paper also discussed different cost-effective decisions. Shaw et al. (2013) proposed a multi-objective goal programming model to optimize the total supply chain cost and direct and indirect carbon emissions for costume industries. Their solutions could help managers to modify their operational strategies to reduce logistics costs and also CFP. One can say that a higher social cost of $\mathrm{CO}_{2}$ emission can force any organization to reduce their CFP. Keeping that in mind, Tseng and Hung (2014) were able to develop a strategic decision-making model for textile industries. They combined the social cost of $\mathrm{CO}_{2}$ emission with the traditional operational cost for a supply chain network and observed that CFP decreases with an increased social cost. Their proposed model was suitable for any multinational company that had manufacturing plants and warehouses in different countries. For further work, they suggested considering different waste management strategies for making a more sustainable supply chain. Ji et al. (2014) observed how ecological footprint and CFP could combine with different supply chain network stages. They also discussed the impact of $\mathrm{CO}_{2}$ emission reduction strategies overproduction, logistics, use and disposal phase.

Apart from optimizing operations, organizations resort to alternative methodologies to meet sustainability obligations. Many organizations consider carbon cap and trade for making low-carbon chance-constrained sustainable supply chains. Garcia-Alvarado et al. (2016) investigated how environmental ventures, increasing production capacity and inventory management communicate to consent to a carbon cap and trade system. Their paper also suggested that investment in emission control technologies could reduce carbon emission over the supply chain network. Shaw et al. (2016) developed a carbon capconstrained sustainable supply chain model and proposed bender decomposition for solving it. This model returned the total emission over the supply chain network and provided information about different materials and energy flows. Their paper also considered different uncertainties over the different phases of the supply chain. The results showed that carbon credit price influenced plants' numbers for any particular organization and its different variable costs. Companies use advanced technologies like drones as substitutes for traditional logistics to reduce carbon emissions. Galve et al. (2016) discussed the life cycle of metallic and plastic waste disposal containers and how that could influence the sustainable supply chain. A mixed-integer sustainable vehicle routing model was proposed to optimize delivery through drones for the last-mile delivery system. They also proposed a genetic algorithm to solve their model, and the result showed that the use of drones could successfully reduce the use of fuel in logistics and reducing the supply chain cost. Multinational companies like Amazon, Google, Wal-Mart are adopting this trending technology in their supply chain. A study proposed sustainable policies for choosing different construction materials in Hong Kong (Hossain et al., 2019). They selected the 12 most popular construction materials and calculated greenhouse gas emissions at their origin location. Their result showed that by using sustainable sourcing, carbon emissions could be reduced by $28 \%$ in the given problem.
Managing carbon footprint

133 
MSCRA

2,3

134

They also proposed the most sustainable locations for importing these 12 construction materials. The discussion of this study enforced the use of more sustainable construction materials. Another sustainable measure adopted in the supply chain is reverse logistics to optimize cost and reduce environmental impact. A study proposed reverse logistics with a hybrid manufacturing system successfully minimizes carbon emission and transportation costs (Aljuneidi and Bulgak, 2019). This model is also helpful in finding operational decisions for different facility location problems.

5.2.2 Supply chain and uncertainty. Researchers explained the need for a resilient supply chain because of different uncertainties throughout the supply chain network. Sustainable and resilient supply chains could explain future uncertainties, which could help analyze different operational strategies to reduce this unwanted emission. There was less literature that discussed sustainability adoption over different supply chain risks. Researchers (Gouda and Saranga, 2018) studied different supply chain risks for six manufactures in 22 countries. Their analysis showed that sustainable practice helped to reduce supply chain risks for emerging markets. Mari et al. (2016) proposed a fuzzy multiobjective supply chain model that considered the textile industries' uncertain demands. They found that sometimes, uncertain demand in real life occurred, and that time supply chain managers mainly focused on the shortages of the network so that they could reduce their losses. This situation increases logistics and other carbon emissions. The same research team (Mari et al., 2014) designed a supply chain network that was resilient and also sustainable. Their proposed model maintained sustainability for unexpected risks over the supply chain like an uncertain environment. They developed a multi-objective goal programming model that handled carbon cost, supply chain cost with disruption cost also taken into account.

\subsection{Research gap}

One of the crucial observations of this literature review is the rise of globalization (international trade) as the primary factor behind adverse environmental impacts, specifically in developing countries. A most cited paper (Lenzen et al., 2012) shows that the demand of developed countries is one of the primary reasons affecting the biodiversity footprint in developing countries. Most developed countries are constrained by their environmental rules and regulations to manufacture specific products that create high $\mathrm{CO}_{2}$ emissions. Hence, they import such products from developing countries where the rules are relaxed comparatively. Researchers claim that because of international trading, more than $30 \%$ of the global species are under threat. They showed that developed countries like the USA were a secondary reason for the biodiversity threat in Mexico. The reason behind this was the high demand for Mexican coffee among US consumers. Their research showed the importance of biodiversity loss over the global supply chain and called for a more sustainable supply chain. Henders et al. (2015) observed that from 2000 to 2011, trading of different commercial agricultural products was the primary reason for tropical deforestation. They analyzed different demand- and supply-side policies and showed that increasing global customer demand is one reason for this trading. Acquaye et al. (2018) observed that carbon emissions are directly proportional to international trade and time (during 1992-2011), specifically for countries like India, China and South Africa. They charge that metal import over the global supply chain was one of the reasons for this situation. They developed a quantitative sustainability measurement model for metal industries and developed some future-oriented hypotheses regarding carbon emission. They also discussed the technicallevel decisions, which were the effects of the CFP management. The existing literature on sustainable supply chain and CFP showed that there was also a gap between organizational decisions and their implementations. The regulatory authorities impose various caps on the 
organization's emissions and wastages to minimize those gaps. Double environmental medium (DEM) regulations helped improve sustainable supply chains; they focus on greenhouse gas emissions and waste disposal to improve the environment. Researchers came up with sustainability reporting and carbon roadmaps to reduce emissions. Caritte et al. (2015) observed that many companies did not disclose their carbon emission information and did not maintain a transparent supply chain network. Sustainability reporting and strict environmental regulation could force organizations to reduce their CFP and other greenhouse gas emission (Caritte et al., 2015). A report estimated that in 2013, some of the USA's largest firms successfully disclosed their supply chain's $22 \%$ carbon emissions. They claimed a vast scope of improvement in emission measurement (Blanco et al., 2016). Kara et al. (2014) surveyed 330 manufacturers from different countries to examine their actual sustainable practices. The survey involved information about firms' operational strategies, decisionmaking abilities and sustainable practices. They observed not only environmental rules but also societal pressure compel firms to adopt sustainable practices and new tools and technologies. In different countries, carbon policies or carbon trading rules are mainly focused on the suppliers or manufacturers of the network. That was the reason manufacturers and suppliers were trying to reduce their carbon emissions. The supply chain network retailers did not directly benefit from this policy, so they usually did not invest their efforts to reduce CFP. Researchers suggested tax-sharing contracts that could directly motivate retailers to reduce their CFPs (Xiao et al., 2016). They also discussed the drawbacks associated with these tax-sharing schemes. The present-day customer prefers low-carbon products, so the retailers take the initiative to promote green products among their customers. Still, there was a gap between sustainable manufacturers and the promotion of low-carbon products. A study proved that different carbon regulations helped develop a more sustainable supply chain, and centralized decision-making helped a two-echelon sustainable supply chain achieve more sustainable products (Liu et al., 2017). A group of researchers successfully calculated the product's CFP over the sustainable supply chain. They used water and fertilizer irrigation machines to verify this methodology (He et al., 2019). In developed countries, the progressive emission tax is an effective way to reduce CFP in the sustainable supply chain. A research team proposed a mathematical model for a sustainable supply chain that considered different environmental policies and progressive emission tax (Yu and Cruz, 2019). This study discussed the effect of different policies over product designing, demand, total emissions and supply chain cost. This study is about a multi-layer supply chain process that helps to identify the consumers' demand at the market so that managers can choose different technologies to fulfill that demand without increasing the carbon emission. The industry players and researchers recognize the importance of proper communication and transparency for reducing the CFP throughout the supply chain. If all the partners of a supply chain like supplier, retailer, consumer and other members discuss their operational problem and strategic decisions throughout the supply chain, they can maintain an optimally integrated supply chain network. This communication can be essential to maintain sustainability. Increased consciousness about global warming among customers demands more sustainable products from distributors and manufacturers. Different stakeholders need to get involved in ensuring supply chain transparency and integration to meet the profit with environmental and social responsiveness (Dahlmann and Roehrich, 2019). Most of the papers discussed sustainable supply chains of developed countries. Analysts need to look at the opposite side of the world to break down various building up nations' sustainable supply chain necessities. New policies are also required for retailers and customers so that they also focus on reducing their carbon emissions. Future research can be on the role of regulations in monitoring and ensuring a sustainable supply chain with a decreased carbon impression. It is additionally seen that the latest and related papers concentrated on three prime industrial sectors: food, electrical and chemical and energy enterprises. In the current literature, there
Managing carbon footprint 
MSCRA

2,3 are very few articles that discussed different uncertainty in the supply chain. A discussion of social effects due to high carbon emission also needs to be considered.

\section{Conclusion, limitations and future research directions}

This organized literature review on a sustainable supply chain and its relationship with CFP policies has brought about various key managerial bits of knowledge for the specialists and future scientists. The study recognizes the implementation of carbon regulation as an essential tool by organizations to achieve sustainable growth. This study also discussed different existing quantitative and qualitative modeling approaches, which helped achieve a sustainable supply chain by reducing CFP. This review identified different research gaps in the existing literature, which help future researchers. From 2010 onward, people are found to be more concerned about global warming, $\mathrm{CO}_{2}$ emissions. We observed that researchers mainly focused on developing new methodologies/tools/technologies to make the existing supply chain more sustainable. Very few articles have identified the gaps in existing practices of existing supply chains and sustainability goals for sustainable development and develop an evaluation system for their sustainable performance. Researchers and organizers focused on environmental impact and economic performance in sustainability studies. Consumer awareness and environmental norms have stimulated work and research in the areas of CFP and sustainability. We can conclude that the target of CFP reduction forced different firms to develop sustainable supply chains. However, sustainability also includes social responsibilities. We witness very few papers that discuss this social performance aspect. From a business point of view, the organization's primary goal is to maximize their profit. However, due to social pressure and regulations, they have to account for different sustainable practices. In future research, one can focus more on the social responsibility aspect of the firms. The study has identified that there are very fewer numbers of research articles that consider different uncertainty in their sustainable operation. COVID-19 also created a massive effect over different supply chains, and researchers should also consider this kind of uncertain situation.

The present study limitations are that it draws a conclusion based on a few journal articles constrained by the Scopus database. Still, it is one of the largest digital databases for all types of materials. We reviewed only 37 most recent and relevant papers that indicate there are as yet numerous things that have not been investigated more profoundly on the issue.

\section{References}

Absi, N., Dauzère-Pérès, S., Kedad-Sidhoum, S., Penz, B. and Rapine, C. (2013), "Lot sizing with carbon emission constraints", European Journal of Operational Research, Vol. 227 No. 1, pp. 55-61.

Acquaye, A., Feng, K., Oppon, E., Salhi, S., Ibn-Mohammed, T., Genovese, A. and Hubacek, K. (2017), "Measuring the environmental sustainability performance of global supply chains: a multiregional input-output analysis for carbon, sulfur oxide, and water footprints", Journal of Environmental Management, Vol. 187, pp. 571-585.

Acquaye, A., Ibn-Mohammed, T., Genovese, A., Afrifa, G.A., Yamoah, F.A. and Oppon, E. (2018), "A quantitative model for environmentally sustainable supply chain performance measurement", European Journal of Operational Research, Vol. 269 No. 1, pp. 188-205.

Ahmed, W. and Sarkar, B. (2019), "Management of next-generation energy using a triple bottom line approach under a supply chain framework", Resources, Conservation and Recycling, Vol. 150, p. 104431.

Aljuneidi, T. and Bulgak, A.A. (2019), "Carbon footprint for designing reverse logistics network with hybrid manufacturing-remanufacturing systems", Journal of Remanufacturing, pp. 1-20.

Allaoui, H., Guo, Y., Choudhary, A. and Bloemhof, J. (2018), "Sustainable agro-food supply chain design using two-stage hybrid multi-objective decision-making approach", Computers and Operations Research, Vol. 89, pp. 369-384. 
Bai, C. and Sarkis, J. (2010), "Integrating sustainability into supplier selection with grey system and rough set methodologies", International Journal of Production Economics, Vol. 124 No. 1, pp. 252-264.

Beamon, B.M. (1999), "Measuring supply chain performance", International Journal of Operations and Production Management.

Benjaafar, S., Li, Y. and Daskin, M. (2012), "Carbon footprint and the management of supply chains: insights from simple models", IEEE Transactions on Automation Science and Engineering, Vol. 10 No. 1, pp. 99-116.

Blanco, C., Caro, F. and Corbett, C.J. (2016), "The state of supply chain carbon footprinting: analysis of

Managing carbon footprint CDP disclosures by US firms", Journal of Cleaner Production, Vol. 135, pp. 1189-1197.

Brundtland, G.H., Khalid, M., Agnelli, S., Al-Athel, S. and Chidzero, B.J.N.Y. (1987), Our Common Future, New York, Vol. 8.

Caniato, F., Caridi, M., Crippa, L. and Moretto, A. (2012), "Environmental sustainability in fashion supply chains: an exploratory case based research", International Journal of Production Economics, Vol. 135 No. 2, pp. 659-670.

Carbon Disclosure Project (2011), CDP Global 500 Report 2011: Accelerating Low Carbon Growth, available at: https://www.demant.com/-/media/demant/main/media-documents/responsibility/ carbon-disclosure-project-2011.pdf.

Caritte, V., Acha, S. and Shah, N. (2015), "Enhancing corporate environmental performance through reporting and roadmaps", Business Strategy and the Environment, Vol. 24 No. 5, pp. 289-308.

Chaabane, A., Ramudhin, A. and Paquet, M. (2012), "Design of sustainable supply chains under the emission trading scheme", International Journal of Production Economics, Vol. 135 No. 1, pp. 37-49.

Chai, Q., Xiao, Z., Lai, K.H. and Zhou, G. (2018), "Can carbon cap and trade mechanism be beneficial for remanufacturing?", International Journal of Production Economics, Vol. 203, pp. 311-321.

Cholette, S. and Venkat, K. (2009), "The energy and carbon intensity of wine distribution: a study of logistical options for delivering wine to consumers", Journal of Cleaner Production, Vol. 17 No. 16, pp. 1401-1413.

Cole, R. and Aitken, J. (2020), "The role of intermediaries in establishing a sustainable supply chain", Journal of Purchasing and Supply Management, Vol. 26 No. 2, p. 100533.

Corbett, C.J. and Klassen, R.D. (2006), "Extending the horizons: environmental excellence as key to improving operations", Manufacturing and Service Operations Management, Vol. 8 No. 1, pp. 5-22.

Cordero, P. (2013), "Carbon footprint estimation for a sustainable improvement of supply chains: state of the art", Journal of Industrial Engineering and Management, Vol. 6 No. 3, pp. 805-813.

Dahlmann, F. and Roehrich, J.K. (2019), "Sustainable supply chain management and partner engagement to manage climate change information", Business Strategy and the Environment, Vol. 28 No. 8, pp. 1632-1647.

Diabat, A., Kannan, D. and Mathiyazhagan, K. (2014), "Analysis of enablers for implementation of sustainable supply chain management-A textile case", Journal of Cleaner Production, Vol. 83, pp. 391-403.

Dubey, R., Gunasekaran, A., Papadopoulos, T., Childe, S.J., Shibin, K.T and Wamba, S.F. (2017), "Sustainable supply chain management: framework and further research directions", Journal of Cleaner Production, Vol. 142, pp. 1119-1130.

Dwivedi, A. and Madaan, J. (2020), "A hybrid approach for modeling the key performance indicators of information facilitated product recovery system", Journal of Modelling in Management.

Dwivedi, A., Agrawal, D. and Madaan, J. (2019), "Sustainable manufacturing evaluation model focusing leather industries in India", Journal of Science and Technology Policy Management.

Dwivedi, A., Agrawal, D. and Madaan, J. (2020), "Identification and prioritization of issues to implementation of information-facilitated product recovery system for a circular economy", Modern Supply Chain Research and Applications. 
MSCRA

2,3
Egilmez, G., Kucukvar, M., Tatari, O. and Bhutta, M.K.S. (2014), "Supply chain sustainability assessment of the US food manufacturing sectors: a life cycle-based Frontier approach", Resources, Conservation and Recycling, Vol. 82, pp. 8-20.

Elkington, J. (1994), "Towards the sustainable corporation: Win-win-win business strategies for sustainable development”, California Management Review, Vol. 36 No. 2, pp. 90-100.

Eltayeb, T.K., Zailani, S. and Ramayah, T. (2011), "Green supply chain initiatives among certified companies in Malaysia and environmental sustainability: Investigating the outcomes", Resources, Conservation and Recycling, Vol. 55 No. 5, pp. 495-506.

Font, X., Tapper, R., Schwartz, K. and Kornilaki, M. (2008), "Sustainable supply chain management in tourism”, Business Strategy and the Environment, Vol. 17 No. 4, pp. 260-271.

Galve, J.E., Elduque, D., Pina, C. and Javierre, C. (2016), "Sustainable supply chain management: the influence of disposal scenarios on the environmental impact of a $2400 \mathrm{~L}$ waste container", Sustainability, Vol. 8 No. 6, p. 564.

Gandhi, S., Mangla, S.K., Kumar, P. and Kumar, D. (2015), "Evaluating factors in implementation of successful green supply chain management using DEMATEL: a case study", International Strategic Management Review, Vol. 3 Nos 1-2, pp. 96-109.

Garcia-Alvarado, M., Paquet, M. and Chaabane, A. (2016), "Joint strategic and tactical planning under the dynamics of a cap-and-trade scheme", IFAC-PapersOnLine, Vol. 49 No. 12, pp. 622-627.

Goetschalcks, M. and Fleischmann, B. (2008), "Strategic network design", Supply Chain Management and Advanced Planning, Springer, Berlin, Heidelberg, pp. 117-132.

Gold, S., Seuring, S. and Beske, P. (2010), "Sustainable supply chain management and interorganizational resources: a literature review", Corporate Social Responsibility and Environmental Management, Vol. 17 No. 4, pp. 230-245.

Gonzalez, C., Korchia, M., Menuet, L. and Urbain, C. (2009), "How do socially responsible consumers consider consumption? An approach with the free associations method", Recherche et Applications en Marketing (English Edition), Vol. 24 No. 3, pp. 25-41.

Gouda, S.K. and Saranga, H. (2018), "Sustainable supply chains for supply chain sustainability: impact of sustainability efforts on supply chain risk", International Journal of Production Research, Vol. 56 No. 17, pp. 5820-5835.

Govindan, K., Khodaverdi, R. and Jafarian, A. (2013), "A fuzzy multi criteria approach for measuring sustainability performance of a supplier based on triple bottom line approach", Journal of Cleaner Production, Vol. 47, pp. 345-354.

Govindan, K., Jafarian, A., Khodaverdi, R. and Devika, K. (2014), "Two-echelon multiple-vehicle location-routing problem with time windows for optimization of sustainable supply chain network of perishable food", International Journal of Production Economics, Vol. 152, pp. 9-28.

Gupta, S., Modgil, S. and Gunasekaran, A. (2020), "Big data in lean six sigma: a review and further research directions", International Journal of Production Research, Vol. 58 No. 3, pp. 947-969.

Haake, H. and Seuring, S. (2009), "Sustainable procurement of minor items-exploring limits to sustainability", Sustainable Development, Vol. 17 No. 5, pp. 284-294.

He, B., Liu, Y., Zeng, L., Wang, S., Zhang, D. and Yu, Q. (2019), "Product carbon footprint across sustainable supply chain”, Journal of Cleaner Production, Vol. 241, p. 118320.

Henders, S., Persson, U.M. and Kastner, T. (2015), "Trading forests: land-use change and carbon emissions embodied in production and exports of forest-risk commodities", Environmental Research Letters, Vol. 10 No. 12, p. 125012.

Hossain, M.U., Sohail, A. and Ng, S.T. (2019), "Developing a GHG-based methodological approach to support the sourcing of sustainable construction materials and products", Resources, Conservation and Recycling, Vol. 145, pp. 160-169.

Hovelaque, V. and Bironneau, L. (2015), "The carbon-constrained EOQ model with carbon emission dependent demand", International Journal of Production Economics, Vol. 164, pp. 285-291. 
Hua, G., Cheng, T.C.E. and Wang, S. (2011), "Managing carbon footprints in inventory management", International Journal of Production Economics, Vol. 132 No. 2, pp. 178-185.

Hubbard, G. (2009), "Measuring organizational performance: beyond the triple bottom line", Business Strategy and the Environment, Vol. 18 No. 3, pp. 177-191.

Intergovernmental Panel on Climate Change (2007), "Climate change 2007: the physical science basis", Agenda, Vol. 6 No. 7, p. 333.

Ji, G., Gunasekaran, A. and Yang, G. (2014), "Constructing sustainable supply chain under double environmental medium regulations", International Journal of Production Economics, Vol. 147, pp. 211-219.

Jiang, Y., Zhao, Y., Dong, M. and Han, S. (2019), "Sustainable supply chain network design with carbon footprint consideration: a case study in China", Mathematical Problems in Engineering, Vol. 2019.

Jørgensen, I.L. and Knudsen, J.S. (2006), Sustainable Competitiveness in Global Value Chains: How do Danish Small Firms Behave, The Copenhagen Centre, Copenhagen.

Kara, S., Ibbotson, S. and Kayis, B. (2014), "Sustainable product development in practice: an international survey", Journal of Manufacturing Technology Management.

Kellner, F. and Igl, J. (2015), "Greenhouse gas reduction in transport: analyzing the carbon dioxide performance of different freight forwarder networks", Journal of Cleaner Production, Vol. 99, pp. 177-191.

Koberg, E. and Longoni, A. (2019), "A systematic review of sustainable supply chain management in global supply chains", Journal of Cleaner Production, Vol. 207, pp. 1084-1098.

Kolk, A. and Pinkse, J. (2008), "A perspective on multinational enterprises and climate change: learning from 'an inconvenient truth'?”, Journal of International Business Studies, Vol. 39 No. 8, pp. 1359-1378.

Kucukvar, M., Cansev, B., Egilmez, G., Onat, N.C. and Samadi, H. (2016), "Energy-climatemanufacturing nexus: new insights from the regional and global supply chains of manufacturing industries", Applied Energy, Vol. 184, pp. 889-904.

Lenzen, M., Moran, D., Kanemoto, K., Foran, B., Lobefaro, L. and Geschke, A. (2012), "International trade drives biodiversity threats in developing nations", Nature, Vol. 486 No. 7401, pp. 109-112.

Liu, Z., Zheng, X.X., Gong, B.G. and Gui, Y.M. (2017), "Joint decision-making and the coordination of a sustainable supply chain in the context of carbon tax regulation and fairness concerns", International Journal of Environmental Research and Public Health, Vol. 14 No. 12, p. 1464.

Luthra, S., Qadri, M.A., Garg, D. and Haleem, A. (2014), "Identification of critical success factors to achieve high green supply chain management performances in Indian automobile industry", International Journal of Logistics Systems and Management 1, Vol. 18 No. 2, pp. 170-199.

Mallidis, I., Dekker, R. and Vlachos, D. (2012), "The impact of greening on supply chain design and cost: a case for a developing region”, Journal of Transport Geography, Vol. 22, pp. 118-128.

Mari, S.I., Lee, Y.H. and Memon, M.S. (2014), "Sustainable and resilient supply chain network design under disruption risks", Sustainability, Vol. 6 No. 10, pp. 6666-6686.

Mari, S.I., Lee, Y.H. and Memon, M.S. (2016), "Sustainable and resilient garment supply chain network design with fuzzy multi-objectives under uncertainty", Sustainability, Vol. 8 No. 10, p. 1038.

Michelsen, O., Fet, A.M. and Dahlsrud, A. (2006), "Eco-efficiency in extended supply chains: a case study of furniture production”, Journal of Environmental Management, Vol. 79 No. 3, pp. 290-297.

Nagurney, A. (2010a), "Optimal supply chain network design and redesign at minimal total cost and with demand satisfaction", International Journal of Production Economics, Vol. 128 No. 1, pp. 200-208. 
MSCRA

2,3

Nagurney, A. (2010b), "Supply chain network design under profit maximization and oligopolistic competition", Transportation Research Part E: Logistics and Transportation Review, Vol. 46 No. 3, pp. 281-294.

Panigrahi, S.S., Bahinipati, B. and Jain, V. (2019), "Sustainable supply chain management", Management of Environmental Quality: An International Journal.

Pelton, R. (2019), "Spatial greenhouse gas emissions from US county corn production", The International Journal of Life Cycle Assessment, Vol. 24 No. 1, pp. 12-25.

Protocol, K. (1997), United Nations Framework Convention on Climate Change, Vol. 19, Kyoto Protocol, Kyoto.

Sadeghi, J. and Haapala, K.R. (2019), "Optimizing a sustainable logistics problem in a renewable energy network using a genetic algorithm”, Opsearch, Vol. 56 No. 1, pp. 73-90.

Sarkar, B., Omair, M. and Choi, S.B. (2018), "A multi-objective optimization of energy, economic, and carbon emission in a production model under sustainable supply chain management", Applied Sciences, Vol. 8 No. 10, p. 1744.

Shardeo, V., Patil, A. and Madaan, J. (2020), "Critical success factors for blockchain technology adoption in freight transportation using fuzzy ANP - modified TISM approach", International Journal of Information Technology and Decision Making. doi: 10.1142/ s0219622020500376.

Shaverdi, M., Heshmati, M.R., Eskandaripour, E. and Tabar, A.A.A. (2013), "Developing sustainable SCM evaluation model using fuzzy AHP in publishing industry", Procedia computer science, Vol. 17, pp. 340-349.

Shaw, K., Shankar, R., Yadav, S.S. and Thakur, L.S. (2013), "Modeling a low-carbon garment supply chain”, Production Planning and Control, Vol. 24 Nos 8-9, pp. 851-865.

Shaw, K., Irfan, M., Shankar, R. and Yadav, S.S. (2016), "Low carbon chance constrained supply chain network design problem: a Benders decomposition based approach", Computers and Industrial Engineering, Vol. 98, pp. 483-497.

Shrivastava, P. (1995), "Ecocentric management for a risk society", Academy of Management Review, Vol. 20 No. 1, pp. 118-137.

Stock, J.R., Boyer, S.L. and Harmon, T. (2010), "Research opportunities in supply chain management", Journal of the Academy of Marketing Science, Vol. 38 No. 1, pp. 32-41.

Sundarakani, B., De Souza, R., Goh, M., Wagner, S.M. and Manikandan, S. (2010), "Modeling carbon footprints across the supply chain", International Journal of Production Economics, Vol. 128 No. 1, pp. 43-50.

Tidy, M., Wang, X. and Hall, M. (2016), “The role of Supplier Relationship Management in reducing Greenhouse Gas emissions from food supply chains: supplier engagement in the UK supermarket sector", Journal of Cleaner Production, Vol. 112, pp. 3294-3305.

Tranfield, D., Denyer, D. and Smart, P. (2003), "Towards a methodology for developing evidenceinformed management knowledge by means of systematic review", British Journal of Management, Vol. 14 No. 3, pp. 207-222.

Tseng, S.C. and Hung, S.W. (2014), "A strategic decision-making model considering the social costs of carbon dioxide emissions for sustainable supply chain management", Journal of Environmental Management, Vol. 133, pp. 315-322.

Wittstruck, D. and Teuteberg, F. (2012), "Understanding the success factors of sustainable supply chain management: empirical evidence from the electrics and electronics industry", Corporate Social Responsibility and Environmental Management, Vol. 19 No. 3, pp. 141-158.

Xiao, Y., Yang, S., Zhang, L. and Kuo, Y.H. (2016), "Supply chain cooperation with price-sensitive demand and environmental impacts", Sustainability, Vol. 8 No. 8, p. 716.

Yu, M. and Cruz, J.M. (2019), "The sustainable supply chain network competition with environmental tax policies", International Journal of Production Economics, Vol. 217, pp. 218-231. 
Zsidisin, G.A. and Siferd, S.P. (2001), "Environmental purchasing: a framework for theory development”, European Journal of Purchasing and Supply Management, Vol. 7 No. 1, pp. 61-73.

Managing carbon footprint

\section{Further reading}

European Commission. EU Emission Trading System (EU ETS) (2010) available at: https://ec.europa. eu/clima/policies/ets_en.

Lensson, G., Gasparski, W., Rok, B., Lacy, P., Jorgensen, A.L. and Knudsen, J.S. (2006), "Sustainable competitiveness in global value chains: how do small Danish firms behave?", Corporate Governance: The International Journal of Business in Society.

\section{Corresponding author}

Piya Ghosh can be contacted at: piyagh@iitk.ac.in 